\title{
TRATAMENTO DE ULCERAÇÕES AFTOSAS RECORRENTES: UMA REVISÃO BIBLIOGRÁFICA
}

\section{TREATMENT OF RECURRING APHTHOUS STOMATITIS: A BIBLIOGRAPHIC REVISION}

\author{
Karine Coelho ${ }^{1}$, Cíntia de Souza Alferes Araújo ${ }^{*}$ \\ $1^{*}$ Universidade Paranaense - UNIPAR, Departamento de Odontologia, Umuarama, PR, \\ Brasil; (44)3621-2844, ramal 1245; e-mail: cíntia@unipar.br \\ Recebido para publicação em 16/11/2005 \\ Aceito para publicação em 08/02/2006
}

\section{RESUMO}

A Estomatite Aftosa Recorrente (EAR) é uma doença benigna comum da cavidade bucal e é encontrada na mucosa não-queratinizada. Vários são os fatores associados a sua etiopatogenia, entretanto pouco é claramente conhecido. Clinicamente, é dividida em três grandes grupos: úlcera aftosa menor (afta vulgar ou de Mikulics); úlcera aftosa maior (Periadenite Mucosa Necrótica Recorrente Cicatrizante ou Afta de Sutton), e úlcera aftosa herpetiforme. O diagnóstico é clínico e nele se observa a caracterização da lesão e os sintomas do paciente. Vários são os tratamentos propostos para as ulcerações aftosas, entretanto os medicamentos utilizados são essencialmente usados com o propósito de realizar o reparo, controlar os sintomas e diminuir a freqüência de recorrências. Pela amplitude e divergências no tratamento dessa doença é que nos propusemos a analisar a literatura recente e as opções para o controle das Estomatites Aftosas Recorrentes (EAR), apresentando as medidas terapêuticas tópicas e sistêmicas, bem como a utilização de laser na resolução dessa patologia.

Palavras-chave: estomatite aftosa recorrente, terapias medicamentosas e laser

\begin{abstract}
Recurring Aphthous Stomatitis (RAS) is an ordinary benign illness in the buccal cavity found in the non-keratinized mucosa. There are a large amount of aspects related to its etiopathogenesis, however, they are not yet well known. It is clinically divided into three major groups: minor aphthous ulcer (ordinary aphtha or Mikulics); major aphthous ulcer (Periodinitis, Recurring Healing Necrotic Mucosa or Sutton Aphtha) and herpetiform aphthous ulcer. The diagnosis is clinical,
\end{abstract}


and the characteristics of the injure and the patient's symptoms are observed. There are several treatments for aphthous ulcers, however, prescribed medicines are essentially used with the aim of controlling the symptoms and to prevent reccurrence. Because of the controversies over the treatment of Recurring Aphthous Stomatitis we carried out an analysis of the existing literature in order to propose topical and systemic therapeutic procedures, as well as the use of laser for the treatment of this pathology.

Key words: recurring aphthous stomatitis, medicine and laser therapies

\section{Introdução}

A úlcera aftosa recorrente (UAR) é uma lesão ulcerada benigna freqüentemente encontrada na mucosa não-queratinizada, como língua, assoalho de boca, mucosa labial, jugal, palato mole e orofaringe (Brice $e t$ al., 2000). Clinicamente apresenta quatro estágios: 0 primeiro é representado por um aspecto sintomático, caracterizado por sensação pruriginosa, dor e aspereza da mucosa nas primeiras 24 (vinte e quatro) horas, sendo que clinicamente não é verificada nenhuma alteração. O segundo estágio é o pré-ulcerativo manifestado por eritema, mácula localizada, com discreta elevação e de consistência dura, pode ser única ou múltipla, com uma membrana superficial circular, halo eritematoso e dor na qual varia a intensidade de paciente para paciente. O terceiro é o ulcerativo onde sua membrana torna-se esbranquiçada e necrótica, essa mudança ocorre num período de 1 (um) a 3 (três) dias. Sobre o assoalho da úlcera forma-se um exsudato fibrinoso, branco-amarelado, o halo eritematoso persiste e a lesão assume aspecto crateriforme. Neste estágio a úlcera atinge seu maior pico de desenvolvimento e a dor vai cedendo, tendo apenas uma sensação de desconforto. O estágio de reparação ocorre espontaneamente por um período em menos de 21 (vinte e um) dias, porém apresentam recidivas. Aúlcera aftosa recorrente (EAR) acomete 20\% (vinte por cento) da população em geral. A primeira manifestação clínica pode ocorrer nos primeiros meses de vida, com mais freqüência nos indivíduos entre 10 (dez) e 20 (vinte) anos de idade e em crianças são bastante comuns na faixa etária de 1 (um) a 3 (três) anos de idade, prevalecendo mais o sexo feminino numa proporção de 2:1 em relação ao sexo masculino (Stanley apud Tommasi 2002).

Existem vários fatores desencadeantes citados na literatura que explicam a causa EAR: aspectos hereditários, psicossomáticos, infecciosos, hormonais (menstruação, gravidez ou período pós-menopausa), traumas, estresse, alergia a certos alimentos, deficiências nutricionais (ferro, vitamina B12 e àcido fólico), alterações hematológicas, casos de ex-fumantes, pois com a suspensão do tabaco a mucosa apresenta-se mais delgada e sensível, aumentando a frequêencia de EAR. A hipótese que mais prevalece é da teoria do complexo auto-imune sendo a mais significativa e aceita hoje. Contudo, por não ter uma uniformidade dos seus efeitos na população, a etiologia ainda édesconhecida (Bordini et al., 2001).

É indispensável à história da lesão relatada pelo paciente e o exame clínico cuidadoso, pois estabelecer o diagnóstico, identificar e tratar as lesões bucais são importantíssimos se considerarmos que o tumor de maior prevalência na boca (carcinoma espinocelular) inicia-se a partir de uma úlcera (Boraks, 1999).

O tratamento é estabelecido pela observação, na verdade não existe um protocolo terapêutico estabelecido que vise á cura das lesões, porém na tentativa de aliviar o quadro sintomatológico, diversos medicamentos são prescritos, o que gera muita dúvida por parte dos profissionais da área. Um ponto crucial é esclarecer ao paciente que o tratamento é paliativo e empírico, pois pela ausência do conhecimento da etiopatogenia, o efeito curativo é restringido, tendo como desafio terapêutico, o controle dos sintomas e a redução da freqüência dos episódios.

O objetivo deste trabalho é apresentar através 
de uma revisão literária, as características gerais da ulcera aftosa recorrente (UAR) bem como enfatizar os tratamentos recentes pesquisados para tal patologia.

\section{Desenvolvimento}

As úlceras aftosas recorrentes (UAR) são lesões da mucosa bucal que muitos pacientes apresentam com freqüência em determinados intervalos de tempo. Correspondem a $90 \%$ de todas as úlceras observadas no cotidiano na prática odontológica, afetando em geral 20\% da população (Silva-Junior et al., 2003). Ocorre em homens e mulheres de todas as idades, raças e regiões geográficas, sendo estimado que 1 em cada 5 indivíduos pode ser afetado ao menos uma vez pelas úlceras aftosas recorrentes (UAR) (Natah et al.,2004).

Acerca das variadas hipóteses sobre sua etiologia, observa-se uma grande dificuldade na determinação de uma causa isolada, que possa explicar, adequadamente, a maioria dos casos encontrados, o que, evidentemente, faz surgir barreiras para um tratamento curativo. Os fatores associados ao desencadeamento da doença são as alterações hormonais, trauma, estresse, alergia a certos alimentos, deficiências nutricionais (ferro, vitamina B12 e ácido fólico), alterações hematológicas, fatores genéticos e agentes microbianos. Entretanto o que se observa é uma forte correlação com alterações imunológicas locais e sistêmicas. (Natah et al., 2004; Onofre et al., 1999).

Ogura et al. (2001) realizou uma pesquisa científica onde avaliou a relação de conservantes alimentares, da deficiência de ferro, cálcio e vitaminas B1, e C com as úlceras aftosas recorrentes (UAR). Observou que além da deficiência de ferro e vitamina B1 há também uma correlação entre a deficiência de cálcio e vitamina $C$, não observando nenhuma correlação positiva no que tange o uso de conservantes.

Estudos comprovam que há associação entre o surgimento de úlceras aftosas recorrentes (UAR) com a ingestão de alimentos como tomates, morangos, nozes, chocolate, glúten, mentolados, melão, agrião, alimentos ácidos, condimentados ou embutidos (Eversole, 1982).

Há anos a etiologia das úlceras aftosas recorrentes (UAR) aparece associada a infecções virais,
Pedersten (1993) realizou um estudo onde analisou a presença de DNA viral em lesões de pacientes com úlcera aftosa recorrente (UAR) observando a presença do vírus Varicela Zóster, da família do herpes vírus humano (HHV) em tais lesões.

Em virtude desta natureza multifatorial, para a equipe odontológica tratar das úlceras aftosas recorrentes (UAR) tornou-se algo complicado, porque sua finalidade seria eliminar a doença, mas sem as causas das lesões ulcerativas, os recursos terapêuticos direcionam-se em reduzir ou até mesmo cessar a inflamação, atenuar a dor da região e acelerar o processo de cicatrização e aumentar o intervalo sem recidiva (Fraiha et al., 2002).

A ulceração aftosa menor ou ainda chamada de afta vulgar ou de Mikulics corresponde à forma mais comum, ocorrendo em $90 \%$ dos casos de úlcera aftosa recorrente (UAR), tendo uma prevalência geral de 5-25\% na população geral. São lesões recorrentes que se apresentam como úlceras circulares rasas, de contorno nítido com borda em geral não elevada, exsudato acinzentado no centro e halo eritematoso ao redor, a dor é presente e sua dimensão de 5 a $10 \mathrm{~mm}$, geralmente única ou em número reduzido, atingindo a mucosa bucal não-queratinizada e desaparecendo entre 7 a 14 dias e com recorrência média de 2 a 3 vezes no ano. Uma outra forma clínica é a ulceração aftosa maior ou Periadenite mucosa necrótica recorrente cicatrizante (Afta de Sutton) aparece mais raramente, ocorrendo em $10 \%$ dos casos. Neste caso a úlcera é profunda, de contorno irregular, com bordas às vezes elevadas, eritema ao redor e exsudato acinzentado ou amarelado no centro, são maiores que as aftas vulgares com dimensão que excedem $10 \mathrm{~mm}$, são múltiplas, podendo atingir mucosa um pouco mais queratinizada, por exemplo a mucosa mastigatória. As dores são intensas e as úlceras terminam seu ciclo de reparo de 10 a 15 dias podendo durar até 6 semanas, deixando cicatriz no local. O último tipo são as ulcerações aftosas herpetiformes, observadas em $10 \%$ dos casos. Clinicamente são úlceras rasas, múltiplas, com diâmetro de $3 \mathrm{~mm}$ que podem coalescer formando uma úlcera de dimensão maior. Aparecem em mucosa não-queratinizada e desaparecem de 7 (sete) a 30 (trinta) dias, deixando cicatriz (Tommasi, 2002; Kerr et al., 2003). Em pacientes com a doença AIDS, as úlceras aftosas recorrentes (UAR) é uma alteração comum de ser obser- 
vada, sendo freqüentemente identificada em palato mole e orofaringe (Muzyka e Glick, 1994).

Para um adequado diagnóstico é necessário que se faça um exame intra-bucal minucioso, verificando número, localização, tamanho e duração da lesão. Muitas vezes em caso de úlceras aftosas menores ou em pouco número, o paciente raramente procura tratamento especializado por ser um quadro leve, onde o desconforto é relativamente pequeno e geralmente são infrequentes, nestes casos a automedicação acaba sendo a opção imediata. Já nos quadros de úlceras aftosas maiores e herpetiformes por serem quadros severos, geralmente há a procura ao cirurgião dentista para resolução e esclarecimento sobre a patologia (Fraiha, 2002).

Opções de tratamento incluem não tratamento, tratamento de doença ou condição sistêmica associada, medicação tópica e medicação sistêmica. As úlceras aftosas recorrentes (UAR) podem se desenvolver secundariamente a doenças sistêmicas como a AIDS, doença de Crohn's, síndrome de Reiter's e Behçet's, nestes casos torna-se necessário um tratamento multiprofissional onde caberá ao cirurgião dentista realizar os cuidados com as alterações bucais e contribuir no diagnóstico precoce da doença.

\section{Terapia tópica}

Em geral, agentes tópicos são preferíveis de certa forma, pela segurança em relação aos efeitos colaterais serem praticamente ausentes pela quantidade administrada e por apresentarem pequena possibilidade de interação medicamentosa, apesar de ser questionada a sua efetividade em relação ao uso de medicação sistêmica (MacPhail, 1997). Sua ação é essencialmente sintomática e são indicados para os casos de estomatite aftosa recorrente menor, para abordagens iniciais e em casos mais severos da doença sendo utilizado como coadjuvante do tratamento sistêmico. (Kignel, 1997). Assim, de acordo com a literatura pesquisada, as principais medidas tópicas são:

Corticosteróides tópicos: são os principais medicamentos sugeridos pelos cirurgiões dentistas por acreditarem que as úlceras aftosas recorrentes (UAR) estão provavelmente relacionadas com os defeitos imunológicos, o tratamento é focado em drogas que possam controlar ou até comandar estas respostas. Sua vantagem é que seu largo alcance inibe a resposta inflamatória qualquer que seja o agente causador, interrompe o ciclo e ainda pode apresentar intervalos maiores sem a doença, porém não consegue impedir a recorrência. (Regezi e Sciubba, 2000).

Uma das substâncias disponíveis em orabase é o acetonido de triancinolona a $0,05 \%$, (Oncilon-A orabase $^{\mathrm{R}}$ ) aplicados nos primeiros sintomas, quatro a seis vezes ao dia (Nassif-Filho et al., 1999; Tuzun et al., 2000). Entretanto, se preferir uma substância de ação mais segura é indicado á combinação de orabase com um corticosteróide mais forte como o gel de fluocinonida a $0,05 \%$, propianato de clobetasol a $0,05 \%$ ou halbetasol. O elixir de dexametasona a $0,01 \%$ é uma outra alternativa utilizada através de bochechos ou gargarejos e no caso das ulcerações aftosas menores há uma boa resposta a esta terapêutica, sendo ainda sugerida para os casos que apresenta múltiplas úlceras e que estão presentes em lugares de difícil acesso como no palato mole ou orofaringe (Neville et al., 2004). Outro corticóide que pode ser útil para casos de úlceras de difícil alcance é o dipropionato de beclometasona presente nas formas de vaporizador ou aerosol, spray e tabletes que podem ser dissolvidos em água (MacPhail, 1997). No caso de medicações tópicas potentes, pode-se associar à composição do fármaco algum agente antifúngico, como a nistatina, uma vez que o uso de corticosteróides tópicos por tempo prolongado, pode provocar o supercrescimento da candida albicans na cavidade bucal (Regezi e Sciubba, 2000).

Antissépticos locais: Entre vários, o sugerido para o tratamento das úlceras aftosas recorrentes (UAR) é o uso de clorexidine a $0,2 \%$ para bochechos ou gel a $1 \%$. Sua vantagem está em reduzir o tempo do ciclo de evolução da úlcera e aumentar o intervalo entre uma lesão e outra. Além de prevenir o paciente de infecções bacterianas ou micótica(Porter et al., 2000; Kerr et al., 2003).

Analgésicos tópicos: O cloridrato de benzidamina ou gel de lidocaína podem ser agentes anestésicos que promovem uma analgesia local. Devem ser massageados no local da lesão para proporcionar um alívio momentâneo da dor. É utilizado principalmente antes das refeições, para diminuir a sensação dolorosa e o paciente poder se nutrir adequadamente (Fraiha et al., 2002). 
Drogas cáusticas: possui a capacidade de necrosar as úlceras e destruir as terminações nervosas livres, proporcionando ao paciente um alívio rápido e uma boa resposta analgésica. Entre tantos, os mais usados de acordo com a literatura são: ácidos tricloroacético à 33\%; nitrato de prata; cloreto de zinco a 20\% $\left(\right.$ Aftagil ${ }^{\mathrm{R}}$ ), fenol e devem ser aplicados com cotonete para evitar maiores agressões ao tecido (Sposto, 1995). Se administrado em quantidade exagerada ou desatenta, pode destruir o tecido adjacente expondo a infecções, que é uma considerável desvantagem, por fazer com que a lesão se transforme numa úlcera traumática química. É importante lembrar que com este tipo de medicamento as úlceras tornam mais profundas e demoram mais para reparar (Boraks, 1999).

Antibióticos locais: demostraram bom desempenho na eliminação de infecções bacterianas secundárias das úlceras aftosas recorrentes, redução da sintomatologia, aceleração da cicatrização e uma resposta muito significativa na diminuição da quantidade de recidivas. A terapêutica mais indicada é de tetraciclina em solução aquosa, dissolvendo $250 \mathrm{mg}$ em $5 \mathrm{ml}$ de água morna, realizando bochechos, durante 21 dias. (Henricsson e Axell, 1985).

\section{Terapia sistêmica}

É indicada para casos de estomatite aftosa recorrente (EAR) maior e herpertiforme, principalmente quando ocorre a coalescência das úlceras. Medicamentos que diminuem a resposta imunológica devem ser prescritos em situações na qual o paciente apresenta-se com sintomatologia dolorosa intensa e/ ou quando as úlceras permanecem por um tempo longo na cavidade bucal (Neville et al., 2004). Na terapia sistêmica o uso dos corticóides também é um dos principais meios de tratamento, especialmente se forem utilizados nos períodos prodrômicos, pois podem fazer com que não haja o desenvolvimento das úlceras. (MacBride, 2000).

Vitamina C: a aplicação endovenosa de doses de $1 \mathrm{a} 2 \mathrm{~g}$ a cada 24 horas durante 15 dias tem se apresentado como um excelente auxiliar no tratamento das úlceras aftosas recorrentes (UAR) uma vez que sua ação torna os surtos mais suaves e aumenta o intervalo entre os ataques (Boraks, 1999).

Corticosteróides: Um medicamento que age com eficiência nos casos de úlceras aftosas recorrentes severa, debilitante ou com um intervalo pequeno entre as recorrências é a prednisona $\left(\right.$ Meticorten $^{\mathrm{R}}$ ). $\mathrm{O}$ tratamento pode ser utilizado por um período de 4 a 5 dias, numa dose máxima de 60-80mg/dia, ou por mais de uma semana diminuindo gradativamente a dose, devendo ser prescrita uma só vez pela manhã a fim de reduzir os efeitos colaterais (Regezi e Sciubba, 2000). É contra-indicado prolongar o uso do regime à base de prednisona por mais de duas semanas, pois ocorrem os efeitos colaterais, como retenção hídrica, euforia, fraqueza muscular e desconforto gástrico. Além de hipertensão, diabetes, glaucoma e infecções (Kignel, 1997).

Talidomida: é considerado o fármaco mais efetivo no tratamento das úlceras aftosas recorrentes (UAR). Este medicamento é um sedativo hipnótico de ação antiinflamatória, age também como supressor da resposta imunológica. Mostrou-se vantajosa sua ação em pacientes HIV + com lesões aftosas. Todavia, devese tomar cuidado e ter uma consideração séria quanto ás reações adversas, como: sedação, neuropatia, diminuição da libido, rash cutâneo, neuropenia, constipação, e teratogenicidade. É contra-indicada também a mulheres em risco de gravidez e crianças. A dose de talidomida indicada no tratamento da úlcera aftosa recorrente severa é de $100 \mathrm{mg} /$ dia (Calabrese e Fleischer, 2000).

Diversas medicações fitoterápicas tem sido utilizadas como recursos terapêuticos para as úlceras aftosas recorrentes (UAR) destaca-se o uso de soluções de própolis, um antibiótico natural, que tem mostrado aceleração na cicatrização de úlceras mucocutâneas, inclusive de úlcera aftosa recorrente (UAR) (Santos, 1999). Recentemente, a Agência Nacional de Vigilância Sanitária (ANVISA) autorizou a utilização de um gel produzido a partir da planta Uncaria Tomentosa (vulgarmente conhecida como unha de gato), que tem apresentado resultados eficazes no tratamento do herpes labial recorrente, já sendo ressaltada a sua utilização para as úlceras aftosas recorrentes (UAR) (Medcenter, 2000).

\section{Terapia com laser}

A terapia com laser de baixa intensidade possibilita que a úlcera aftosa recorrente estacione seu ciclo 
inicial, regrida e que ocorra uma recuperação mais rápida e menos dolorosa. Sua irradiação proporciona um estímulo em nível de fibroblastos, com produção de fibras colágenas mais ordenadas, verificando clinicamente aceleração na cicatrização e logo após a primeira aplicação o paciente já relata ter cessado a dor. Com relação à forma de tratamento, a seleção do laser está correlacionada com o comprimento de onda e potência do aparelho, bem como a extensão da área da lesão. Dentre os lasers de baixa intensidade os mais utilizados para intuito terapêutico são os de HélioNeônio (He-Ne), cujo comprimento de onda de emissão é 632nm e o de Arseneto de Gálio-Alumínio (Ga-Al-As ), cujo comprimento de onda está entre 650 ou 950nm. Sob o ponto de vista físico, é útil definir que a ação dos lasers de baixa intensidade não apresenta efeitos térmicos. Outra forma de tratamento seria com os lasers de alta intensidade, apresentando uma variedade de modelos, exemplo Neonídio (Nd:YAG). Entretanto, seu custo é mais elevado e diante do ponto de vista físico, sua ação proporciona efeitos térmicos. (Cecchini, 2000).

\section{Considerações finais}

Com o levantamento da literatura pesquisada, conclui-se que não existe um tratamento específico que promova a cura das úlceras aftosas recorrentes. Assim, todos os medicamentos propostos, proporcionam um resultado satisfatório, mas não completo, pois não foi descoberta qualquer forma de tratamento que seja consistentemente bem-sucedida na prevenção das recidivas. Uma vez que a etiopatogenia das aftas é multifatorial, torna-se necessário que o cirurgião dentista realize um adequado exame clínico do paciente, e seja crítico diante desta gama de terapias, para que assim possa prescrever um medicamento que se adeque a real condição do paciente amenizando o quadro clínico das lesões. Muito ainda deve ser investigado a respeito desta patologia, para que se alcance a cura efetiva.

\section{REFERÊNCIAS}

1. BORAKS, S. Diagnóstico Bucal. São Paulo: Artes Médicas,
1999. p.98-102.

2. BORDINI, P. J.; GROSSO, S. F. B.; CARMO, C. Estomatologia na clínica infantil - Principais alterações bucais. Revista da Associação Paulista de Cirurgiões Dentistas, 55: 366-370, 2001.

3. CALABRESE L. e FLEISCHER A.B. Thalidomic: current and potential clinical applications. Am. J. Med., 108 (6): 48795,2000

4. CASTRO, A. L. Estomatologia. São Paulo: Santos, 2000. p. 118-122.

5. COLEMAN, G. C. Princípios de Diagnóstico Bucal. Rio de Janeiro: Guanabara koogan, 1996.

6. CECCHINI, R. C. Uma Nova Alternativa Para o Tratamento da Úlcera Aftosa e Herpes Labial”. RGO, 5 (2):8-13, 2000.

7. CHERUBINI, K., GOUVEIA, A.P.C.; MOTTA, C.S. Ulceração aftosa recorrente: revisão da literatura. Revista Odonto Ciência, 18:196-199, 2003.

8. FRAIHA, P. M. Estomatite aftosa recorrente: Revisão bibliográfica. Revista Brasileira de Otorrinolaringologia, 68:1$14,2002$.

9. GOLDMAN-GILMAN, A.; HARDMAN, J.G; LIMBIRD, L.E. As Bases Farmacológicas da Terapêutica. 10 ed. Rio de Janeiro: Guanabara Koogan, 2003.

10. HENRICSSON, V. e AXELL T. Treatment of recurrent aphthous ulcers with Aureomycin mouth rinse or Zendium dentifrice. Acta Odontol Scand, 43(1): 47-52, 1985

11. KEER, A. R.; DREXEL, C.A.; SPIELMAN, A.I. The efficay and safety of $50 \mathrm{mg}$ penicillin $\mathrm{G}$ potassium troches for recurrent aphthous ulcers. Oral Surg. Oral Med. Oral pathol, 96: 685-694, 2003.

12. KIGNEL, S. Diagnóstico Bucal. São Paulo: Robe,1997. p. 133-139.

13. KIGNEL, S.; OREIRA, C.A.; ARAÚJO E.C.M.; MISTRO, F.Z. Ulcerações aftosas recorrentes - aspectos clínicos e considerações sobre tratamento. Revista Paulista de Odontologia, 3:16-18, 2000.

14. KOROLKOVAS, A. Dicionário Terapêutico Guanabara. 1996/1997 ed. Rio de Janeiro: Guanabara Koogan, 1996.

15. MAGALHÃES, M. H. Orientando o paciente: Aftas. Revista da Associação Paulista de Cirurgiões Dentistas, 53: 471, 1999.

16. McPHAIL, L. Topical and sytemic therapy for recurrent aphthous stomatitis. Seminar in Cutaneous Medicine and Surgery, 16(4):301-7, 1997.

17. McBRIDE, D.R. Management of aphthous ulcers. Am. Physician, 62 (1): 149-54, 160, 2000

18. MUZYCA, B.C. e GLICK, M. Major aphthous ulcers in patients with HIV disease. Oral Surg. Oral Med. Oral pathol., 77:116-20,1994. 
19. NASSIF-FILHO, A.C. N.; BETTEGA, S.G.; LUNEDO, S.; GORTS, F.; MAESTRI, J.E.; ABICALAFFE, M.D. Estomatite Aftoide Recidivante: Revisão e Proposta de Protocolo no seu Atendimento. Arquivos da Fundação Otorrinolaringologista, 3(4): 172-6, 1999.

20. NASPITZ, N.; ZEZELL, DM; FALTIN-JUNIOR, K. Avaliação do efeito terapêutico do laser de Ga-Al-As, sobre lesões provocadas por aparelho ortodôntico fixo na mucosa da cavidade oral. Revista Goiana de Ortodontia, 5: 7-13, 2000.

21. NATAH, S.S.; KONTTINEN, Y.T.; ENATTAH, N.S.; ASHAMMAKHI, N.; SHARKEY, K.A.; HAYRINENIMMONEN, R. Recurrent aphthous ulcers today: a review of the growing knowledge. Int j Oral Maxillofac Surg, 33 (3): 22134, 2004.

22. NEVILLE, B.W.; DAMM, D. D.;ALLEN, C. M.; BOUQUOT, J. E Patologia Oral \& maxilofacial. Rio de Janeiro: Guanabara Koogan, 1998. p. 230-233.

23. ONOFRE, M.A; MASSUCATO, M.E.S.; NAVARRO, C.M; SPOSTO, M.R. Úlceras bucais: Diagnósticos diferencial e conduta clínica. Revista Odonto 2000, 3: 24-29, 2000.

24. PEDERSEN, A. Recurrent aphthous ulceration: virological and immunological aspects. APMIS Suppl, 37:1-37, 1993

25. PEDERSEN, A.; MADSEN, H.O.; VESTERGAARD, B.F., RYDER, L.P. Varicellazoster virus DNA in recurrent aphthous ulcers. Scand J Dent Res, 101:311-3, 1993.

26. PORTER, S.R.; HEGARTY, A.; KALIAKATSOU, F.; HODGSON, T.A.; SCULLY, C. RecurrentAphthous Stomatitis.
Clinics in Dermatology, 18: 569-578, 2000.

27. REGEZI, J. A.; SCIUBBA, J. J. Patologia bucal: Correlações Clínicopatológicas. 3 ed. Rio de Janeiro: Guanabara Koogan, 2000. p. 42-48.

28. SANTOS, V. R., Própolis: antibiótico natural alternativo em Odontologia? Revista do CROMG, 5:192-195, 1999.

29. SILVA-JUNIOR, J. C. Úlcera aftosa recorrente - como auxiliar o paciente? Revista da Associação Paulista de Cirurgiões Dentistas, 57: 193, 2003.

30. SONIS, S. T. Medicina Oral. Rio de Janeiro: Guanabara Koogan, 1995. p. 299-302.

31. SPOSTO, M. R., Úlcerações Aftosas Recorrentes. RGO, 43: 77-80, 1995.

32. STÊVÃO, E. L. Ulceração aftosa recorrente: uma entrada uma identidade patológica de etiologia controversa. Revista Odonto Ciência. 23: 99-104, 1997

33.TOMMASI, A. F. Diagnóstico em Patologia Bucal.3 ed. São Paulo: Pancast, 2002, p.139-145.

34. TUZUN, B; TUZUN, Y; WOLF, R. Oral Disorders: Unapproved Treatments or Indications. Clinics in Dermatology, 18: 197-200, 2000.

35. ZEGARELLI, E. V. Diagnóstico das Doenças da Boca e dos Maxilares. 2 ed. Rio de Janeiro: Guanabara Koogan, 1982. p. 350-354.

36. Anvisa autoriza remédio fitoterápico contra herpes labial. Disponível em www.medcenter-2000. Acessado em 23/08/05. 